\title{
Clinical Presentation of Epilepsy among Adult Sudanese Epileptic Patients Seen In Sheik Mohamed Kheirs Friday Epileptic Clinic-SUDAN
}

\author{
Hussein $A^{1}$, ElTahir $A^{1}$, Yasin $F^{2}$, Malkaldar $M^{3}$, Amira Sidig, Mubark $B^{3}$, Ahmed E ${ }^{3}$, Hashim $M^{4}$
}

\begin{abstract}
Objective: To study the pattern of clinical presentation of epilepsy among adult Sudanese epileptic patients.

Methods: 120 patients with epilepsy were included in a prospective cross-sectional study. Setting: The study was conducted at Sheik Mohamed Kheir Friday Epileptic Clinic Duration: May 2003-Oct 2006.

Results: Males were (54.15\%) while females were $(45.85 \%)$. In 80 patients $(67 \%)$ no cause was identified. Cerebrovascular accident was found to be the commonest risk factor, 24 patients $(20 \%)$ had a family history of epilepsy. 103 patients had generalized epilepsy while 18 patients had focal epilepsy. The prodromal symptoms and neurological signs were common among patients with partial epilepsy. 78 patients (64.8\%) showed abnormal EEG. 12 patients (10\%) with generalize epilepsy had abnormal CT of the brain, while $50 \%$ of those who had focal epilepsy had abnormal $\mathrm{C} T$ of the brain.

Conclusion: Generalized epilepsy is more common than partial epilepsy. Prodromal symptoms and neurological signs were common among patients with partial epilepsy. EEG and CT Brain play an important role in supporting the diagnosis of epilepsy.
\end{abstract}

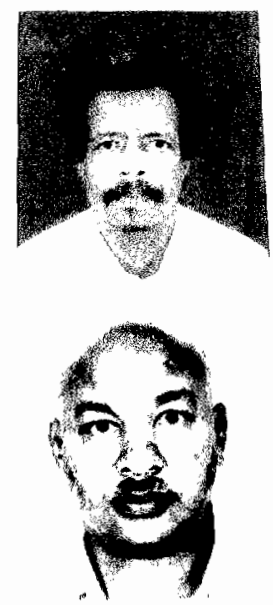

\section{Introduction}

Epilepsy is a clinical syndrome characterized by abnormal movement with or without loss of consciousness. It can be either generalized or focal and is due to disturbance of spread of electrical discharge of cortical neurons ${ }^{1-2}$. Epilepsy is either idiopathic or secondary ${ }^{3}$. It can also be classified according to the site of spread of electrical activity e.g. occipital, frontal and temporal, but the most important classification depend on the spread of electrical activity e.g. generalized or focal epilepsy with their different types ${ }^{4}$.

\section{Objective}

The objective is to study the presentation pattern of epilepsy among adult Sudanese epileptic patients.

Inclusion criteria: Adult Sudanese patients aged 18 years or older attending the clinic were enrolled in the study All patients gave consent to participate in the study.

Methodology

This is a prospective cross sectional study conducted on Friday clinic as a part of the activities of Sheikh Mohammed Khier's mosque in Omdruman, Sudan. In six weeks time 120 patients were seen by one house officer, two medical registrars and two neurologists.

1. Faculty of Medicine, University of Khartoum

2. Faculty of Medicine, Omdurman Islamic University, Sudan

3. Ministry Of Health. Registrar of Medicine.

4. House officer,

Corespondance to Abbashar Hussein:

E-mail: abbashar59@yahoo.com
Detailed history and proper clinical examination were done. The investigations included urine \& stool urinalysis, complete blood count, serum urea, liver function test, random blood glucose, calcium, magnesium, EEG and CT brain. EEG analysis was done by a neurophysiologist, CT brain was reported by two nueroradiologists. These patients were followed up for three years.

\section{Results}

Out of 120 patients $65(54.15 \%)$ were males. 72 patients were from Khartoum and most of them where students, house wife's and unemployed persons

Table 1: Age distribution

$\begin{array}{cc}\begin{array}{c}\text { Age } \\ \text { group }\end{array} & \begin{array}{c}\text { Number of patients } \\ \mathrm{n}=120\end{array} \\ 18-20 & 40 \\ 21-30 & 26 \\ 31-40 & 20 \\ 41-50 & 9 \\ 51-60 & 8 \\ 61-70 & 10 \\ 71-80 & 7\end{array}$

Twenty four $(20 \%)$ patients had a family history of Epilepsy. Generalized and focal epilepsy were seen in $103(85.8 \%)$ and $17(14.2 \%)$ patients respectively. 17 patients had secondary generalized epilepsy, $12(10 \%)$ had complex partial seizure and $5(4.2 \%)$ patients had simple partial seizure. 


\section{References}

1. Berkovic SF, McIntosh A, Howell R, et al. Familial temporal lobe epilepsy: A common disorder identified in twins. Ann Neurol 1996; 40:227-235.

2. Raymond AA, Fish DR, Sisodiya SM et al. Abnormalities of gyration, heterotopias, tuberous sclerosis, focal cortical dysplasia, microdysgenesis, dysembryoplastic neuroepithelial tumour and dysgenesis of the archicortex in epilepsy. Brain 1995; 118:629-660.

3. Palmini A, Andermann F, Olivier A, et al. Focal neuronal migration disorders and intractable epilepsy: a study of 30 patients. Ann Neurol 1991; 30:741-749.

4. King MA, Newton MR, Fitt GJ et al. Epileptology of the first seizure: Study of 200 consecutive cases. Epilepsia 1996; 37(suppl.-5):82.

5.Lüders HO, Burgess R, Noachtar S. Expanding the international classification of seizures to provide localization information. Neurology 1993; 43:16501655 .
6. Lüders $\mathrm{H}$, Acharya $\mathrm{J}$, Baumgartner, et al. Semiological seizure classification. Epilepsia 1998; 39:1006-1013.

7. Engel J. Classification of the international league against epilepsy: Time for reappraisal. Epilepsia 1998; 39:1014-1017.

8. Placencia M, Shorvon S, Paredes V, et al. Epileptic seizures in an Andean region in equador: incidence and prevalence and regional variation. Brain 1992; 115:771-782.

9. Cockrell OC, Johnson AL, Sander JWAS et al. Prognosis of epilepsy: a review and further analysis of the first nine years of the British National General Practice Study of epilepsy, a prospective population based study. Epilepsia 1997; 38:31-46.

10. Woodbury DM, Woodbury JW. Effects of vagal stimulation on experimentally induced seizures in rats. Epilepsia 1990; 31 (suppl 2): S7-S19.

11. Abbasher.H, Ammer E. The pattern of clinical presentation of epilepsy Emirate Med J 2006;22:5455. 